\title{
Pengaruh Motivasi Kerja terhadap Profesionalitas Guru Sekolah Dasar di Pedesaan
}

\author{
Edi Harapan \\ Universitas PGRI Palembang, Palembang, Sumatera Selatan, Indonesia \\ Corresponding author: Edi Harapan (e-mail: ehara205@gmail.com)
}

\begin{abstract}
Abstrak: Penelitian ini bertujuan untuk mengetahui pengaruh motivasi kerja terhadap profesionalitas guru sekolah dasar negeri (SDN) di pedesaan. Penelitian dilakukan di Kecamatan Babat Toman, Kabupaten Musi Banyasin, Sumatera Selatan. Populasi pen elitian yaitu 111 guru SDN yang telah bersertifikat pendidik. Sampel penelitian berjumlah 53 orang yang diambil secara ajak dari populasi berdasarkan rumus Taro Yaname dan Slovin dengan presisi $10 \%$. Hasil penelitian menunjukkan motivasi kerja guru di pedesaaan masih rendah dan belum memberikan pengaruh yang signifikan terhadap profesionalitasnya. Selain itu, guru juga mengalami hambatan untuk mengembangkan profesionalitasnya. Penelitian ini menyarankan agar pemerintah daerah memberikan stimulus dan dorongan kepada guru di pedesaan untuk senantiasa mengembangkan profesionalitasnya.
\end{abstract}

Kata Kunci: motivasi kerja, profesionalisme guru

\section{The Effect of Work Motivation on Teacher Professionalism at Public Elementary Schools in Rural Areas}

\begin{abstract}
This study aims to examine the influence of work motivation on teacher professionalism at rural public elementary schools. The study took place in the Babat Toman Subdistrict, Musi Banyasin Regency, South Sumatra. The population of this study was 111 rural elementary school teachers who have held a teaching certificate. 53 of them were selected randomly using the Taro Yaname dan Slovin formula with $10 \%$ precision. Data were collected using a questionnaire and then analysed using a quantitative data analysis method. This study found that work motivation of rural teachers is still low and does not significantly influence their professionalism. In addition, they experienced barriers in developing their professionalism. This study suggests that local governments should motivate rural teachers to continuously develop their professionalism.
\end{abstract}

Keywords: work motivation, teacher professionalism

\section{PENDAHULUAN}

Motivasi merupakan salah satu komponen penting bagi tiap individu. Motivasi merupakan faktor-faktor yang mengarahkan dan mendorong perilaku atau keinginan seseorang untuk melakukan suatu kegiatan yang dinyatakan dalam bentuk usaha yang keras atau lemah 
(Badeni, 2014:76). Motivasi setiap orang akan berbeda, tergantung kepada minatnya masing masing. Motivasi terdiri dari berbagai jenis, beberapa diantaranya yaitu motivasi berprestasi, berusaha, dan bekerja. Motivasi kerja seseorang dimulai dari dalam diri. Se seorang juga menanamkan semangat dan keinginan diri untuk terus maju. Dorongan dan seman gat inilah yang membuat orang ingin lebih maju atau ingin sukses dalam menjalani profesi atau pekerjaannya. Tugas guru cukup berat. Selain mengajar, guru juga bertugas sebagai pendidik, pembimbing, fasilitator, dan motivator.

Guru berhadapan dengan puluhan bahkan ratusan siswa setiap hari, memerlukan motivasi kerja yang tinggi. Motivasi guru bisa dari eksternal maupun internal. Motivasi eksternal bersumber dari status sosial, pendapatan, penghargaan, dan kehormatan yang diberikan oleh masyarakat. Motivasi internal dapat bersumber dari minat, bakat, kompeten si, pendidikan, panggilan jiwa dan pengabdian yang tulus terhadap profesi yang dijalaninya. Zulkifli (2014) menyatakan bahwa motivasi kerja berperan penting dalam upaya meningkatkan profesionalitas seorang guru. Harapan (2007) mengatakan bahwa kemampuan profesional dipengaruhi oleh beberapa faktor, salah satunya yaitu motivasi motivasi berprestasi.

Tugas utama guru adalah melakukan pendidikan dan pengajaran agar siswanya menjadi berilmu, berkarakter dan mandiri dalam menghadapi masa depan. Guru perlu motivasi yang tinggi untuk melaksanakan tugasnya dengan baik. Motivasi ini perlu selalu dipertahankan agar selalu pada level yang tinggi. Soetjipto dan Kosasi (2018) mengatakan bahwa karakteristik guru profesional yaitu memiliki keterampilan mengajar, disiplin yang tinggi, lulus uji kompetensi dan memiliki sertifikat pendidik.

Namun, banyak guru yang bertugas di pedesaan motivasi kerjanya masih rendah. Guru di pedesaan guru-guru yang bermukim di desa (Ahmad, 2003). Hasil observasi menunjukkan bahwa kinerja mereka yang telah bersertifikat pendidik, yang oleh karenanya mendapat tunjangan profesi tidak lebih baik dari guru yang belum bersertifikat. Di saat bersamaan, hasil wawancara menunjukkan (1) ada guru yang trauma bekerja karena ada kejadian buruk pada guru; (2) tindakan guru saat mengajar dinilai sebagai suatu tindakan kekerasan pada siswa, orang tua siswa marah kepada tindakan guru dan memukulnya di sekolah; (3) guru dihadang oleh siswa pada saat pulang dari mengajar, dan (4) perilaku tidak pantas lainnya seperti pengancaman atas keselamatan guru yang dilakukan oleh oknumoknum tertentu yang tidak bertanggung jawab. Kesemuanya tersebut berdampak pada kinerja guru yang relatif masih rendah. 
Permasalahan yang terjadi melatarbelakangi penelitian tentang motivasi kerja dan profesionalitas guru Sekolah Dasar Negeri (SDN) yang ada di pedesaan. Rumusan pertanyaan penelitian ini yaitu "seberapa besar pengaruh motivasi kerja terhadap profesionalitas guru SDN di pedesaan?" Penelitian ini dilakukan di semua SDN yang terdapat di Kecamatan Babat Toman Kabupaten Musi Banyuasin Provinsi Sumatera Selatan. Di Kecamatan ini terdapat 28 SD yang semuanya berstatus sekolah Negeri yang tersebar di 17 desa dengan jumlah keseluruhan guru 338 orang. Dari semua guru tersebut, ada 111 orang (sekitar 33\%) yang telah memegang sertifikat pendidik.

\section{METODE PENELITIAN}

Penelitian ini dilaksanakan di semua sekolah dasar yang ada di Kecamatan Babat Toman Kabupaten Musi Banyuasin Provinsi Sumatera Selatan. Metode dalam penelitian ini yaitu metode kuantitatif dengan pendekatan survey.

Populasi penelitian yaitu seluruh guru SDN bersertifikat yang ada di wilayah Kecamatan Babat Toman. Jumlah totalnya yaitu 111 orang yang tersebar di 28 sekolah. Dari 111 orang tersebut, 53 orang diambil sebagai sampel penelitian dengan teknik pengambilan sampling secara acak menggunakan rumus dari Taro Yaname dan Slovin dengan presisi 10\% (Riduwan dan Engkos, 2011:49).

Terdapat beragam teknik pengumpulan data Menurut Sugiyono (2017:156-165) teknik pengumpulan data dapat dilakukan dengan observasi, wawancara, menyebarkan angket, mencari dokumen pendukung, dan/atau melakukan penggabungan dari semua teknik tersebut sehingga tidak ada lagi data-data yang meragukan. Pengumpulan data dalam penelitian ini dilakukan dengan menyebarkan angket. Angket merupakan teknik pengumpulan data yang dilakukan dengan cara memberi seperangkat pernyataan tertulis kepada responden untuk dijawabnya (Sugiyono, 2017:162).

Angket yang digunakan merupakan angket tertutup. Angket ini mengukur motivasi kerja guru yang bersertifikat pendidik dari sepuluh indikator, yaitu: (1) pencapaian kerja, (2) pengakuan, (3) bertanggung jawab, (4) kemajuan, (5) gaji, (6) jaminan keamanan, (7) kondisi kerja, (8) status sosial kemasyarakatan, (9) kejelasan prosedur kerja, dan (10) kualitas hubungan sesama guru dan kepala sekolah. Profesionalitas kerja guru diukur dari tujuh indikator, yaitu: (1) keterampilan mengajar yang baik; (2) wawasan yang luas; (3) menguasai kurikulum; (4) menguasai media pembelajaran; (5) penguasaan teknologi; (6) menjadi teladan bagi orang lain; dan (7) berkepribadian. Sebelum digunakan, angket terlebih dulu diuji validitas dan reliabilitasnya. 
Sebelum angket digunakan, validitas dan reabilitasnya diuji terlebih dahulu. Pertama, angket diuji validitas kontennya oleh pakar. Setelah angket dinyatakan lay ak, lalu dilakukan uji coba lapangan kepada 30 guru SDN di Kecamatan Babat Toman yang telah bersertifikat. 30 guru tersebut merupakan bagian dari populasi yang tidak terpilih sebagai sampel penelitian. Uji coba validitas instrumen dilakukan dengan penghitungan statistik menggunakan rumus korelasi product moment. Uji reliabilitas instrumen dilakukan dengan penghitungan statistik menggunakan rumus Cronbach's Alpha. Hasil pengujian menunjukkan bahwa semua item angket valid. Angket juga terbukti reliabel.

Analisis data dilakukan melalui pengujian hipotesis asosiatif yang terdiri dari beberapa langkah, yaitu: (1) uji koefisien determinasi, yang di dalamnya menyangkut uji korelasi (R), uji pengaruh ( $R$ Square), uji Adjusted $R$ Square, dan uji Standard Error of the Estimate; dan (2) uji analisis regresi yang di dalamnya memuat tentang: uji B (Beta) dan Std. Error Unstandardized Coefficients; uji B (Beta) Standardized Coefficients; uji t; dan uji Signifikansi (Sig). Kedua pengujian ini dilakukan dengan menggunakan bantuan program SPSS for Window. Ver 22.00. Uji persyaratan atas data dilakukan sebelum data dianalisis. Uji persyaratan ini terdiri dari (1) uji normalitas dan (2) uji linearitas garis regresi.

\section{HASIL}

Uji normalitas dilakukan dengan menggunakan metode Liliefors dan Kolmogorov-Smirnov Z (Kesumawati, dan Aridanu, 2017:74) yang hasilnya dapat dilihat pada tabel berikut.

Tabel1.Ha sil ujinormalitas

\begin{tabular}{|c|c|c|c|}
\hline & & Profesionalitas Guru & Motivasi Kerja \\
\hline $\mathrm{N}$ & & 53 & 53 \\
\hline \multirow[t]{2}{*}{ NormalParameters ${ }^{\mathrm{a}}$} & Mean & 76.04 & 75.64 \\
\hline & Std. Deviation & 9.401 & 11.030 \\
\hline \multirow[t]{3}{*}{ Most Extreme Differences } & Absolute & .093 & .105 \\
\hline & Positive & .081 & .105 \\
\hline & Negative & -.093 & -.092 \\
\hline Kolmogorov-SmirnovZ & & .675 & .768 \\
\hline Asymp. Sig. (2-tailed) & & .752 & .598 \\
\hline
\end{tabular}

Data yang berdistribusi normal dapat juga dilihat melalui grafik $P-P$ plot dari data variable motivasi kerja dan profesionalitas guru sebagai berikut. 


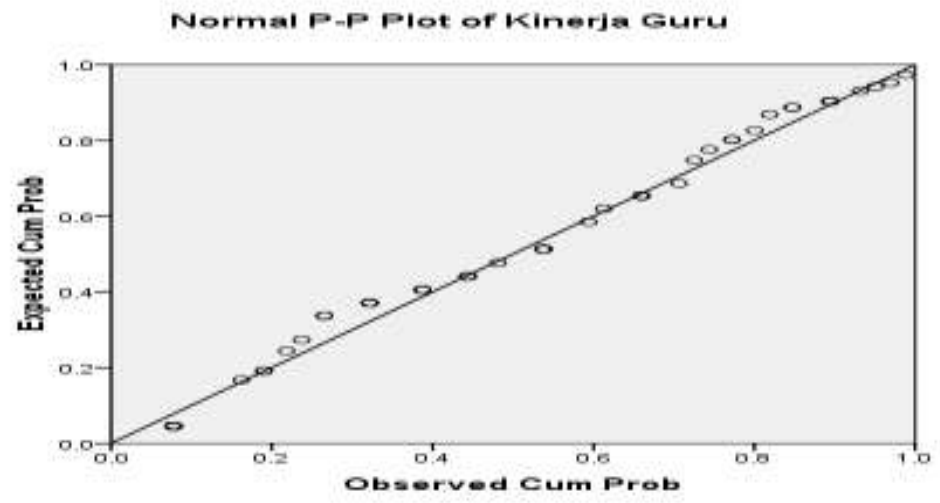

Gambar 1. Grafik P-Plot variabelmotivasi kerja $(X)$

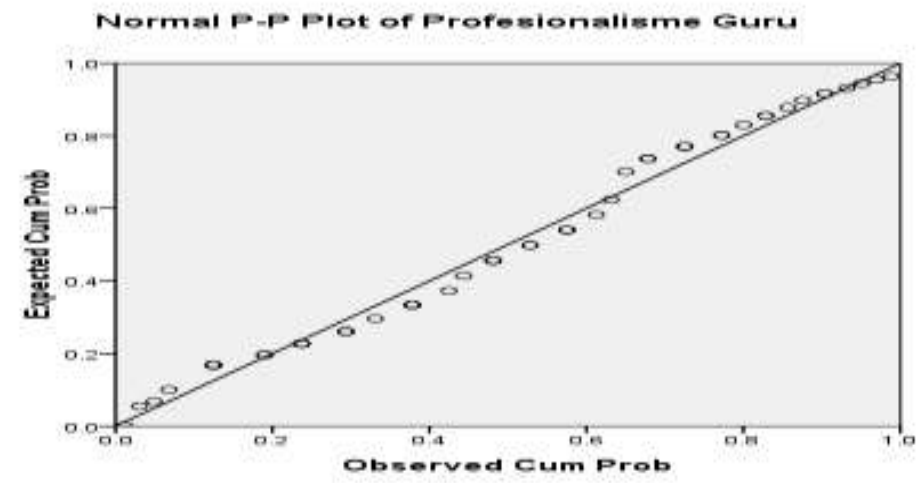

Gambar 2. Gra fik P-Plot variabel profesionalitas guru (y)

Gambar 1 dan 2 menunjukkan titik-titik ploting selalu mengikuti dan mendekati garis diagonalnya. Jika titik-titik atau data berada di dekat atau mengikuti garis diagonalnya, maka nilai residual kedua variabel berdistribusi normal.

Uji linieritas digunakan untuk mengetahui apakah variabel yang diteliti memiliki hubungan yang linier atau tidak (Kesumawati dan Aridanu, 2017:74). Hasil uji linieritas hubungan motivasi kerja dengan profesionalitas guru adalah sebagai berikut.

Tabel2. Ha sil uji linierita s motivasi kerja $(X)$

\begin{tabular}{|c|c|c|c|c|c|c|c|}
\hline & & & $\begin{array}{l}\text { Sum of } \\
\text { Squares }\end{array}$ & Df & $\begin{array}{c}\text { Mean } \\
\text { Square }\end{array}$ & $\mathrm{F}$ & Sig. \\
\hline \multirow{5}{*}{$\begin{array}{l}\text { Profesionalitas Guru } \\
* \text { Motivasi Kerja }\end{array}$} & \multirow[t]{3}{*}{ Between Groups } & (Combined) & 2984.725 & 25 & 119.389 & 2.001 & .040 \\
\hline & & Linearity & 438.065 & 1 & 438.065 & 7.341 & .012 \\
\hline & & Deviation from Linearity & 2546.659 & 24 & 106.111 & 1.778 & .075 \\
\hline & Within Groups & & 1611.200 & 27 & 59.674 & & \\
\hline & Total & & 4595.925 & 52 & & & \\
\hline
\end{tabular}

Berdasarkan hasil uji linieritas pada tabel 2, variabel motivasi kerja dengan profesionalitas guru telah memenuhi persyaratan analisis sehingga dapat diproses ke tahap analisis selanjutnya. 
Hipotesis penelitian ini adalah motivasi kerja guru SD bersertifikat berpengaruh terhadap profesionalitas guru SD di pedesaan. Pengujian hipotesis dilakukan dengan mengukur koefisien determinasi diperoleh dari nilai koefisien korelasi $(R)$ digunakan untuk mengukur kekuatan hubungan antara dua variabel (Kesumawati, dkk., 2018). Hasil penghitungan dari variabel motivasi kerja $(X)$ dan profesionalitas guru $(Y)$ terlihat pada tabel

3.

Tabel3. Model summary koefisien determinasi $X-Y$

\begin{tabular}{lccrr}
\hline Model & R & R Square & $\begin{array}{c}\text { Adjusted } \\
\text { Square }\end{array}$ & $\begin{array}{c}\text { Std. Error of the } \\
\text { Estimate }\end{array}$ \\
\hline 1 & $.309^{\text {a }}$ & .095 & .078 & 9.029 \\
\hline a.Predictors: (Constant), X(motivasi kerja)
\end{tabular}

Tabel 3 menunjukkan bahwa nilai $R$ (korelasi) untuk motivasi kerja guru bersertifikat sebesar $0,309^{\text {a }}$. Ini berarti motivasi kerja dengan nilai profesionalitas guru SD di pedesaan yang telah bersertifikat pendidik menunjukkan kategori hubungan yang "rendah" karena berada pada range 0,20 - 0,399. Hal ini didasarkan pada pedoman intepretasi tabel koefisien korelasi (Sugiyono, 2015). Tabel 3 di atas juga menunjukkan tingkat pengaruh variabel motivasi kerja guru bersertifikat pendidik terhadap profesionalitasnya dapat dilihat dari koefisien determinasi $\left(R^{2}\right)$. Hasil pengujian menunjukkan bahwa pengaruh yang disumbangkan oleh motivasi kerja terhadap profesionalitas guru SD di pedesaan y ang telah bersertifikat pendidik $\left(R^{2}\right)$ sebesar 0.095 atau $9,5 \%$ berada dalam kategori rendah (Su warno, 1986).

Hasil analisis uji keberartian (kebermaknaan) hubungan motivasi kerja dengan profesionalitas guru bersertifikat pendidik disajikan dalam tabel 4 berikut.

Tabel4. Coefficients ${ }^{a}$ analisis regresi

\begin{tabular}{|c|c|c|c|c|c|c|}
\hline \multirow{2}{*}{\multicolumn{2}{|c|}{ Model }} & \multicolumn{2}{|c|}{ Unstandardized Coefficients } & $\begin{array}{l}\text { Standardized } \\
\text { Coefficients }\end{array}$ & \multirow[b]{2}{*}{$\mathrm{T}$} & \multirow[b]{2}{*}{ Sig. } \\
\hline & & B & Std.Error & Beta & & \\
\hline \multirow[t]{2}{*}{1} & (Constant) & 56.133 & 8.676 & & 6.470 & .000 \\
\hline & $\mathrm{X}$ (motivasikerja) & .263 & .114 & .309 & 2.318 & .024 \\
\hline
\end{tabular}

a. Dependent variable: $\mathrm{Y}$ (profesionalitas guru)

Tabel 4 menunjukkan bahwa hasil motivasi kerja berpengaruh tidak signifikan terhadap profesionalitas guru SD bersertifikat pendidik di pedesaan. Hasil analisis ini menunjukkan bahwa motivasi kerja mempengaruhi profesionalitas guru, tetapi pengaruh tersebut tidak signifikansi. 


\section{PEMBAHASAN}

Hasil penelitian memperlihatkan bahwa motivasi kerja guru SD di pedesaan yang telah bersertifikat pendidik hubungan rendah dan tidak signifikan terhadap kemampuan profesionalitasnya $\left(0.309^{a}\right)$. Kontribusi yang disumbangkan oleh motivasi kerja guru di pedesaan juga tidak signifikan, yaitu 9,5\%. Temuan penelitian ini dapat menjelaskan sebagian penyebab hasil penelitian yang dilakukan kepada guru-guru di seluruh wilayah Provinsi Sumatera Selatan sebelumnya bahwa "kinerja guru tidak mengalami peningkatan meskipun telah menerima sertifikat pendidik." (Harapan, 2016).

Motivasi kerja guru SD pedesaan yang bersertifikat pendidik di Kecamatan Babat Toman yang masih rendah perlu mendapat perhatian serius dari semua pihak. Perhatian ini dapat berasal dari pemerintah, masyarakat, dan pimpinan sekolah. Perhatian ini penting mengingat motivasi kerja merupakan salah satu faktor utama pendorong profesionalitas kerja seseorang. Isroni (2016) yang menemukan bahwa terdapat hubungan positif variabel motivasi kerja, masa kerja, dan kesejahteraan dengan profesionalisme guru, baik secara parsial maupun secara simultan. Dengan kata lain, "guru-guru yang rendah tingkat motivasi kerjanya tidak akan professional menjalankan tugas dan tanggung jawabnya (Rohma, dkk., 2020).”

Sutrisno (2017) menyatakan bahwa motivasi kerja merupakan faktor yang pendorong seorang guru melakukan suatu aktivitas tertentu dalam menjalankan tugasnya. Winardi (2019:292) menjelaskan motivasi muncul karena adanya kebutuhan (need), aspirasi (aspiration), dan keinginan (desire). Motivasi kerja merupakan proses mempengaruhi kebutuhan dasar atau dorongan yang memberikan semangat, menyalurkan, dan mempertahankan perilaku. Badeni (2014:77) menyatakan bahwa motivasi kerja merupakan suatu proses yang menghasilkan suatu intensitas, arah/tujuan, dan ketentuan individual dalam mencapai tujuan. Secara umum semua orang membutuhkan motivasi untuk giat bekerja. Motivasi kerja bagi guru SD yang bersertifikat pendidik merupakan salah satu faktor dalam dirinya yang memberikan semangat kerja. Hamalik (2012:72) menegaskan bahwa, "sangat penting bagi guru mempunyai motivasi kerja.” Motivasi kerja dapat menimbulkan semangat atau dorongan bekerja individu atau kelompok terhadap pekerjaan guna mencapai tujuan" (Aqib, 2012:73). Selanjutnya, Wahyudi (2012:37) berpendapat, "motivasi kerja menjadi faktor pendorong dari diri seseorang untuk melaksanakan pekerjaannya. Uno (2013:28) mengemukakan motivasi kerja adalah proses yang dilakukan untuk menggerakkan guru agar perilaku mereka dapat diarahkan pada upaya-upaya nyata untuk mencapai tujuan y ang telah ditetapkan. Sejalan dengan pendapat Suryana (2012:9), “motivasi kerja menjadi pend orong 
bagi guru untuk melakukan pekerjaan sehingga tercapai sesuai dengan rencana”. Guru yang memiliki motivasi kerja yang tinggi senantiasa mengerjakan pekerjaan sesuai dengan rencana, menyelesaikan pekerjaan tepat waktu sesuai dengan tujuan yang telah ditentukan sebelumnya.

Guru-guru SD pedesaan yang telah bersertifikat pendidik dalam penelitian ini tinggal di pedesaan. Kondisi kerja mereka secara umum kurang mendukung untuk bekerja profesional. Sekolah tempat mereka bertugas rata-rata kekurangan guru. Selain itu, kualifikasi guru masih di bawah standar nasional dan banyak yang tidak linier sebagai guru SD. Akibatnya, seringkali seorang guru harus mengajar lebih dari satu kelas. Para guru SD di pedesaan juga sulit meningkatkan kemampuan mengajarnya. Guru yang in gin melanjutk an pendidikan mengalami beberapa tantangan dan hambatan. Pemerintah pusat dan daerah melakukan pembatasan kepada guru-guru yang akan melanjutkan pendidikan. Mereka tidak diperkenankan kuliah di perguruan tinggi yang jauh dari tempat tinggalnya. Jarak maksi mal yang diijinkan hanya 60 kilometer dari sekolah. Di saat ini jarak ibukota kecamatan ke ibukota provinsi adalah 180 kilometer. Selain itu akses jalan ke ibukota provinsi juga jauh dan sering mengalami kemacetan.

Pemerintah daerah juga tidak memberikan kesempatan kepada guru-guru untuk belajar penuh waktu dan meninggalkan tugas mengajarnya. Mereka yang akan melanjutkan pendidikannya, hanya diberi ijin belajar dengan ketentuan tidak boleh meninggalkan tugas utama. Penyebabnya yaitu jumlah guru SD di pedesaan masih sangat kurang dari standar ideal. Di sisi lain, perguruan tinggi penyelenggara pendidikan guru dilarang menyelenggarakan kelas jauh yang terpisah dari kampus induknya. Akses ini hanya diberikan kepada Universitas Terbuka (UT) dengan menyelenggarakan Unit Program Belajar Jarak Jauh -Universitas Terbuka (UPBJJ-UT). Kebijakan ini semakin melemahkan harapan guru guru di daerah untuk meningkatkan kemampuan profesionalnya.

\section{SIMPULAN}

Sumbangan dari motivasi kerja terhadap profesionalitas guru SD di pedesaan dalam wilay ah Kecamatan Babat Toman yang telah bersertifikat pendidik, rendah dan tidak signifikan. Selain itu, para guru SD di daerah ini juga menghadapi keterbatasan untuk mengemban gkan profesionalitasnya. Mereka tidak diijinkan untuk studi lanjut penuh waktu. Selain itu, akses jalan menuju provinsi di mana perguruan tinggi menyelenggarakan pendidikan dan pelatihan untuk guru juga masih sulit. 
Penelitian ini menyarankan kepada pimpinan pendidikan, pemerintah pusat dan daerah, masyarakat, orang tua, komite sekolah untuk berpartisipasi secara nyata dalam upaya meningkatkan profesionalitas guru yang telah bersertifikat pendidikan melalui peningkatan motivasi kerja. Terlebih, selama ini motivasi kerja setiap guru hanya berasal dari dalam dirinya (internal), sedangkan motivasi yang berasal dari luar diri (eksternal) belum dilaksanakan secara maksimal oleh pimpinan. Upaya yang dapat dilakukan antara lain dengan membuka akses seluas-luasnya kepada guru untuk meningkatkan pendidikannya melalui tugas belajar dan ijin belajar; mengembangkan diri; memberi perlindungan kepada guru yang melaksanakan tugas profesinya; dan membuat kebijakan yang berpihak kepada guru.

\section{DAFTAR PUSTAKA}

Ahmad, Abu. (2003). Ilmu sosial dasar. Jakarta: Rineka Cipta.

Aqib, Zainal. (2012). Pendidikan karakter di sekolah membangun karakter. kepribadian anak. Bandung: Yrama Widya.

Badeni. (2014). Kepemimpinan dan perilaku organisasi. Bandung: Alfabeta.

Harapan, Edi. (2016). Kinerja guru pasca sertifikasi (studi pada guru penerima sertifikasi di provinsi sumatera selatan). Prosiding Seminar Nasional PPs Universitas PGRI Palembang.

Harapan, Edi. (2007). Faktor-faktor determinan yang mempengaruhi profesionalitas dosen pts. Disertasi. Bandung: UPI Bandung (Tidak diterbitkan).

Hamalik, Oemar. (2012). Manajemen pengembangan kurikulum. Bandung: Remaja Rosdakarya.

Isroni. (2016). Hubungan motivasi kerja, masa kerja, dan kesejahteraan dengan profesionalisme guru sekolah dasar negeri di kecamatan grabag kabupaten magelang. Tesis.Universitas PGRI Semarang.

Kesumawati, Nila., Margareta, A., \& Sari, N. (2018). Pengantar statistik penelitian. Jak arta: Raja Grafindo Persada.

Kesumawati, Nila \& Aridanu, Ichwan. (2017). Statistik parametrik penelitian pendidikan. Palembang: Noer Fikri.

Riduwan., \& Achmad, E. K. (2011). Cara menggunakan dan memaknai path analysis (analisis jalur), Edisi Revisi, Cetakan Ketiga. Bandung: Alfabeta.

Rohma, Siti., Harapan, Edi., \& Wardiah, Dessy. (2020). The influence of school-based management and teacher's professionalism toward teacher's performance. Journal of Social Work and Science Education, 1(1), 13-23. Retrieved from https://ejournal.karinosseff.org/index.php/jswse/article/view/6

Sugiyono. (2017). Metode penelitian kuantitatif, kualitatif, dan $r \& d$. Bandung: Alfabeta.

Sugiyono. (2015). Metode penelitian administrasi. Bandung: Alfabeta.

Suryana, Dede. (2012). Pengaruh kepemimpinan dan pengembangan karir terhadap motivasi kerja: Kasus karyawan PT. Indorama Synthetic Tbk. Artikel Jurnal Sains Manajemen \& Akuntansi 4.

Soetjipto \& Kosasi, Raflis. (2018). Profesi keguruan. Jakarta: Rineka Cipta. 
Sutrisno, Edy. (2017). Manajemen sumber daya manusia. Jakarta: Prenandamedia Group.

Suwarno, Bambang. (1986). Pengukuran pengaruh dalam ilmu statistik. Bandung: UPI Tidak diterbitkan.

Undang-undang Nomor 14 Tahun 2005 tentang Guru dan Dosen.

Uno, Hamzah B. (2013). Teori motivasi dan pengukurannya. Jakarta: Bumi Aksara.

Wahyudi, Bambang. (2012). Manajemen sumber daya manusia. Bandung: Alfabeta.

Winardi. (2019). Manajemen perilaku organisasi. Jakarta: Prenadamedia Group.

Zulkifli. (2014). Motivasi kerja, sertifikasi, kesejahteraan dan kinerja guru. Artikel. Jurnal Psikologi Indonesia Untag Surabaya. 